\title{
Study Of Soil Particle Size Effectine The Scour Reduction Behind Hydraulic Structures
}

\author{
Mamdouh Ahmed Dardeer \\ Lecturer of Irrigation and Hydraulics Faculty of Engineering, Al-Azhar University, Egypt
}

\begin{abstract}
.
Many ways have been studied to energy dissipate behind vertical gates, but not recommended that best size of soil grains downstream hydraulic structure, especially with the use of nonconventional sill Y-shaped.

Theoretically, studies have been conducted using numerical analysis method to determine the relationships between variables and the various parameters. An intensive experimental study has been conducted in glassed wall flume with square cross section of $(30 \mathrm{~cm} \times 30 \mathrm{~cm})$ and length of $4 \mathrm{~m}$. Different conditions of Froude's number' $\left(\mathrm{F}_{\mathrm{r}}\right)$ from 5.38 to 10.4. In this study nonconventional sill has been studied with three inclined angles $\left(45^{\circ}, 30^{\circ}, 15^{\circ}\right)$ and the relative distance $\left(\mathrm{L}_{b} / \mathrm{L}_{\mathrm{f}}=0.27,0.22,0.17\right)$ and the best results were given for an angle of 30 with $\mathrm{L}_{\mathrm{b}} / \mathrm{L}_{\mathrm{f}}=$ 0.27 to reduce the scour depth and length. The soil remaining after the scour completion has been collected behind the vertical gates and sieve analysis was done. The scour area was backfilled was with the same specifications as the soil remaining. Re-experiments have been done with the same conditions, to detect the best case. Measurements using ultrasonic device were taken, analyzed, presented and discussed. It was deduced that the optimum particle size of soil for backfilling behind the hydraulic structures, where $F_{r}$ ranges from Fr from 5.38 to 10.4 is relative soil diameter $\mathrm{D}_{50} / \mathrm{B}$ from $2.8 \times 10^{-4}$ to $1.5 \times 10^{-3}$ and relative soil diameter, the scour depth and length will be decreased by percentage $50 \%$ to $60 \%$, and $40 \%$ to $60 \%$, respectively.
\end{abstract}

Keywords: Scour, characteristics, soil particle size, non-conventional sill, water quality.

\section{1- Introduction}


One of the most important structures in the world is the water structures, any crack or collapse will lead to unknown damage or disasters. Many studies have been conducted on water structures and elements that affect these structures. One of the most vital factors that affect water structures is the giant energy generated downstream these structures, that evaporates part of the natural phenomenon (hydraulic leap), meanwhile the remaining part of this energy rushes towards the run able to destroy this property. Published researches were collected and analyzed. In the researches, it was clear that:

The main feature of the hydraulic jump is the unexpected transition of rapid shallow flow to slow moving flow with the increase of the fluid surface known as a transition from supercritical to subcritical flow. (Chanson2004)

The length of the hydraulic jump that results from the rapid velocity leads to bed scour behind these structures. One of the major challenges that threaten the stability of the hydraulic control structures is the scour. That's why the apron has to be a long enough in order to dissipate this energy, and the acts of erosion behind this structure. The most important task of the hydraulic designers is the way to dissipate a major part of the water energy behind the vertical gate with the use of effective tools. In 2003 Shri Ram Chaurasia declared that the problems in the design of stilling basin require knowledge of different elements of the hydraulic jump with known values as intensity discharge and the loss of energy. El-Masry has detected the double line of angles baffles and fully angle baffled floor with angle blocks, to reduce (2001) the scour downstream heading up structures. Abouel Atta, Nahla (1986) has studied experimental investigations to detect the effect of length and location on the beds roughened on flow features. Abdellatif (1983) has suggested the use of $1.6 \mathrm{~cm}$ cubic copper blocks to be put staggered in order to dissipate the energy of the hydraulic jump. Ali (2004) has conducted an intensive study to detect the efficiency of the parabolic sill in dissipating the energy of the hydraulic jump. The effect of side flow on the energy downstream sluice gate has been investigated by Abd Elgalil (2006). In 2008 Ali studied using the aprons of formed surfaces as energy dissipaters downstream hydraulic structures. In 2004 Ahmed Helmy has suggested the use of Y-shaped as non-traditional sill for energy dissipater's downstream hydraulic structures. In 2019 Mostafa Ali Optimum size of the soil particles around Bridge Piers in Curved Channels. Mostafa Ali (2019) has concluded that the optimum particle size of soil 
around bridge pier in curved channels with zero degrees for piers' rotation around its axis in the direction of flow, for relative soil diameter $\mathrm{D}_{50} / \mathrm{B}$ ranges from $2.33 \times 10^{-4}$ to $3 \times 10^{-3}$ where the scour depth decreases by a percentage range from $20 \%$ to $40 \%$. In 2020 Ahmed Helmy deduced that the optimum size around bridge piers in curved channels, is achieved for relative soil diameter $\mathrm{D}_{50} / \mathrm{B}$ that ranges from $2.33 \times 10^{-4}$ to $3 \times 10^{-3}$ where the scour depth decreases by a percentage ranges from $20 \%$ to $40 \%$.

\section{2- Research Objective}

The main objective of this research is to detect the suitable soil particle size for the backfill behind the hydraulic structures that reduces the depth and length and to compare between the different cases.

\section{3- Theoretical approach}

Theoretical studies have conducted that the use of numerical analysis method Buckingham's $\pi$ - theorem to determine the relationships between the different parameters. All parameters and geometry are shown in fig.1. Functional relationships are achieved between the relative lengths of $\left(L_{\mathrm{s}} / \mathrm{L}_{\mathrm{sw}}\right)$, and the relative scour depth $\left(\mathrm{d}_{\mathrm{s}} / \mathrm{d}_{\mathrm{sw}}\right)$, with Fraud's number $\left(\mathrm{F}_{\mathrm{r}}\right)$. as follows:

$\mathrm{ds}=\Phi\left(\mathrm{L}_{\mathrm{f}}, \mathrm{Lb}, \mathrm{L}_{\mathrm{j}}, \mathrm{t}, \mathrm{h}, \mathrm{B}, \mathrm{y}_{1}, \mathrm{y}_{\mathrm{n}}, \Delta \mathrm{E}, \mathrm{Q}, \rho, \mathrm{g}, \mu, \mathrm{S} . \mathrm{G}, \varnothing, \mathrm{D}_{\mathrm{s}}, \mathrm{L}_{\mathrm{s}}, \mathrm{L}_{\mathrm{m}}\right)$

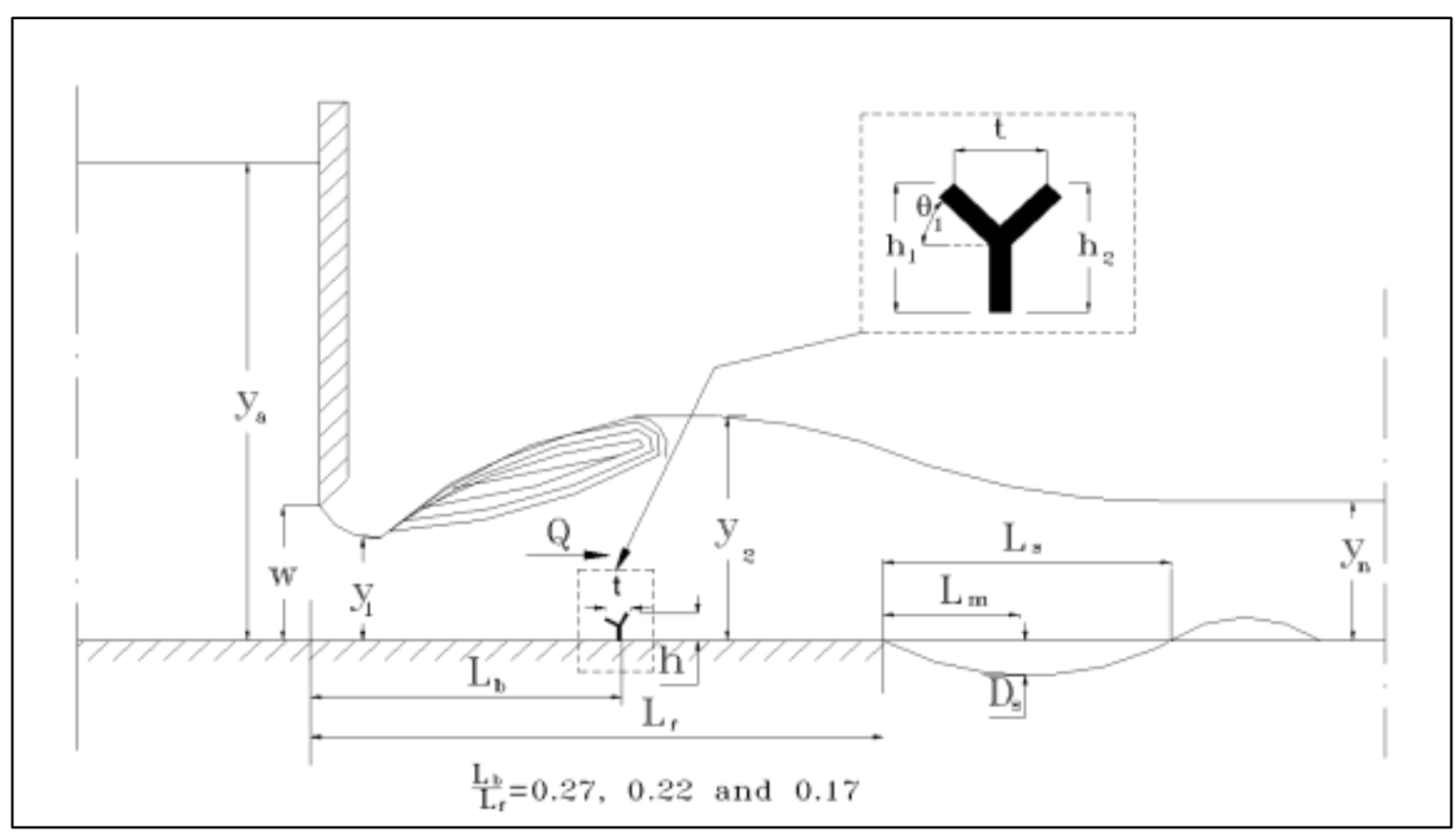

Fig. 1: Definition sketch of Y-Shape sill and all parameters 
According to Buckingham $\pi$-theorem, the general form of the relationship between these variables as follows:

$$
\frac{d s}{s w}=\varnothing\left(\frac{L s}{l s w}, \frac{L j}{y 1}, \frac{L b}{L f}, \frac{t}{h}, \frac{D_{50}}{B}, \frac{T}{T o}, F_{r}\right)
$$

\section{4- Experimental Works}

The experimental procedures in an experimental channel has been conducted by the Hydraulic Laboratory of the Faculty of Engineering, Al-Azhar University Cairo, Egypt, Fig (2). The shape of the experimental channel is rectangular cross section of $(30 \times 30 \mathrm{~cm})$ and its length is $4 \mathrm{~m}$. The support of the channel was frames of steel with transparent vertical side. The models of the test were designed to examine the pier's shape and the equilibrium scour condition. The Experiments were conducted under different conditions for all $\left(\mathrm{F}_{\mathrm{r}}\right)$ from 5.38 to 10.4. The depth and length of the scour was measured and the remaining soil in bed are collected and sieve analyses for the soil collected are done and compared to the original soil that had been investigated before. After that re-experiments are done with the use the collected soil. Then re-measuring the previous variables is done.

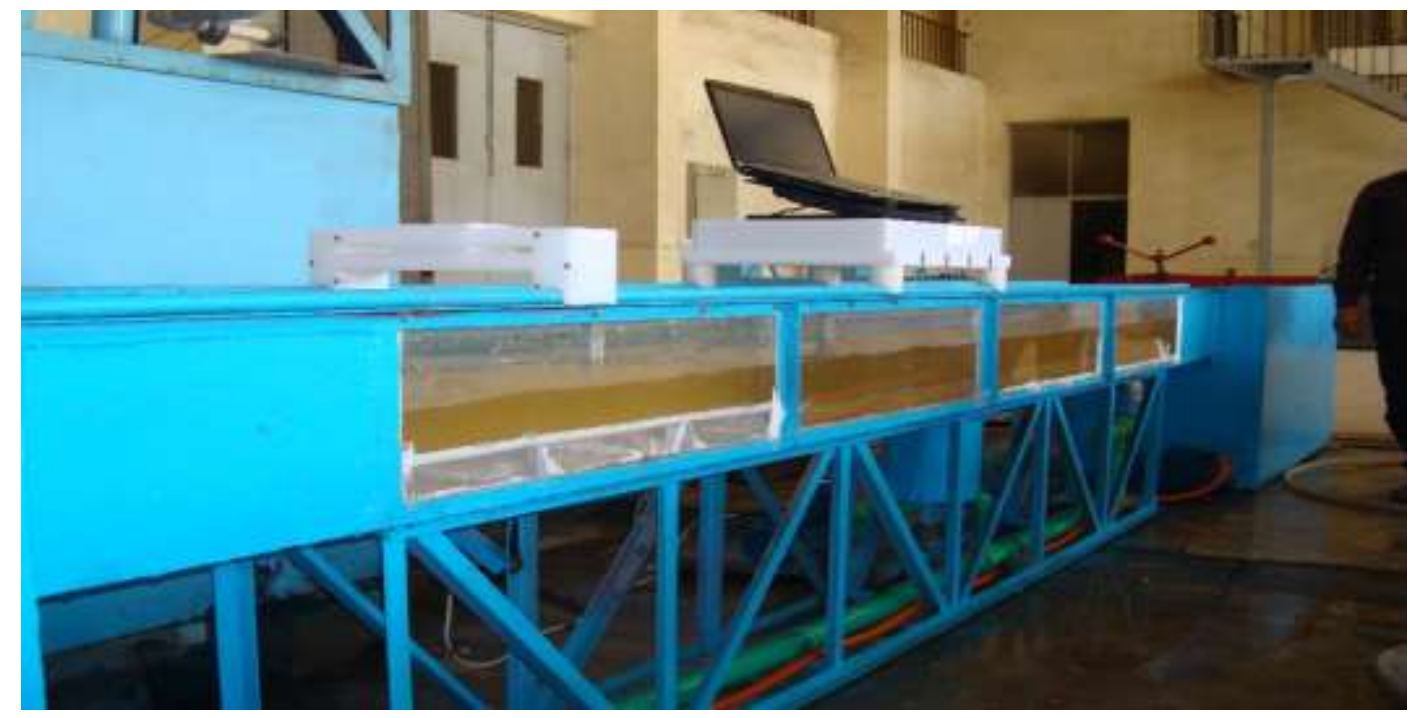

Fig 2: General view of the experimental flume

\section{5- Analysis}


Fifty experiments were carried out, where five (5) different discharges for the best angle and position to give the best results in the reduction of the scour length and depth, Sieve analysis was drawn and we get $\mathrm{D}_{15}, \mathrm{D}_{50}, \mathrm{D}_{85}$. Measurements and observations were done, recognized and the photos were taken. These measurements, observations and photos were documented, archived then analyzed and plotted on graphs to be interpreted as follows:

\section{A-Sieve analysis Results}

The remaining soil was collected after the pouring behind hydraulic structures was completed and a sieve analysis was performed for the case that gave best results to reduce the depth and length of scour. Sieve analyzes were mapped by which $\mathrm{D}_{15}, \mathrm{D}_{50}$ and $\mathrm{D}_{85}$ were determined for flow conditions and different shapes, some of which are shown in Figs. (3) and (4). Note that $\mathrm{D}_{50}, \mathrm{D}_{15}$ and $\mathrm{D}_{85}$ are suitable for backfilling behind hydraulic structures with sill angle $30^{\circ}$, position $\mathrm{L}_{\mathrm{b}} / \mathrm{L}_{\mathrm{f}}=0.27$ and different flow conditions. After analyzing the numbers, note that the optimum grain size distribution ranging between $0.28 \mathrm{~m}$ to $1.5 \mathrm{~mm}$.

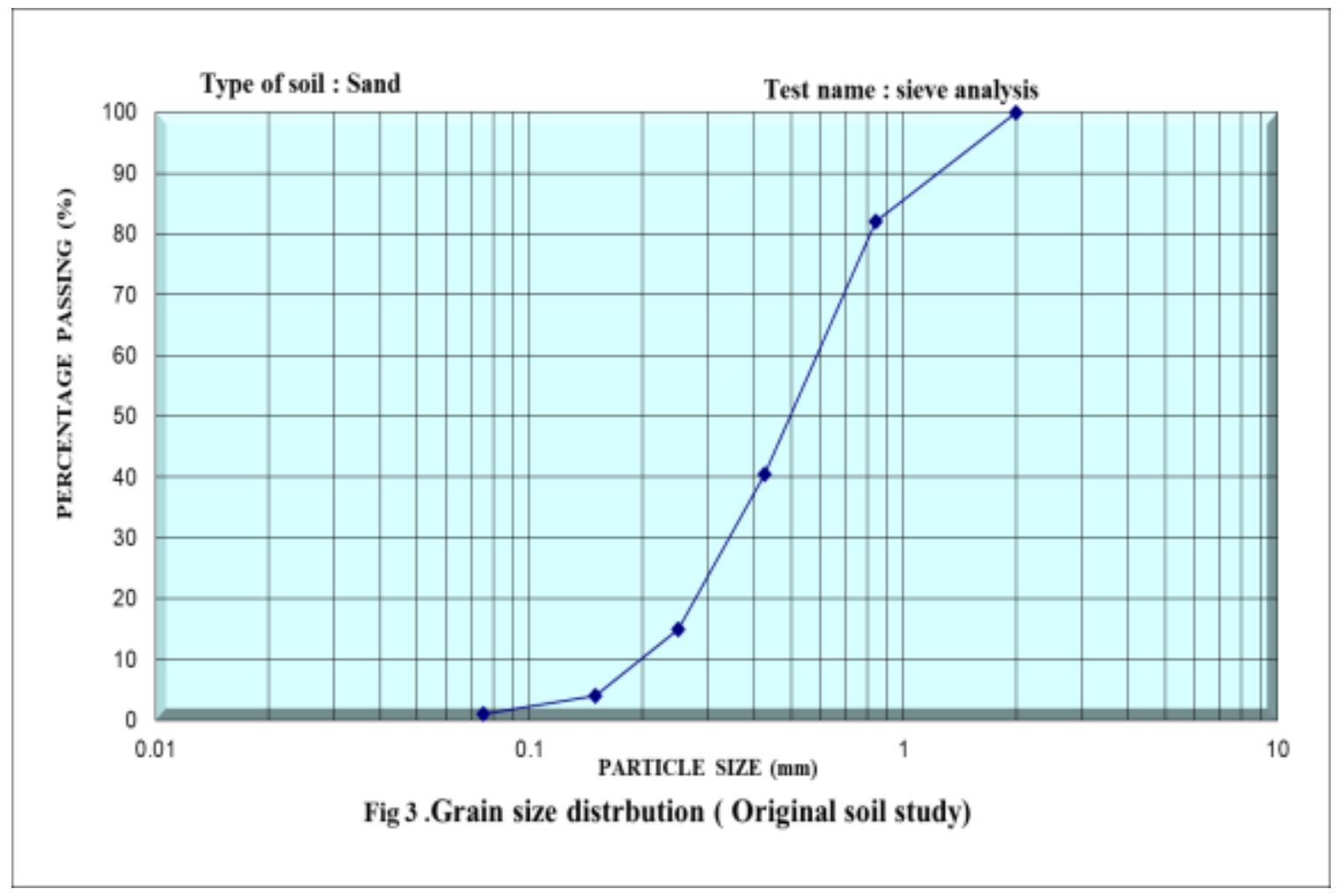




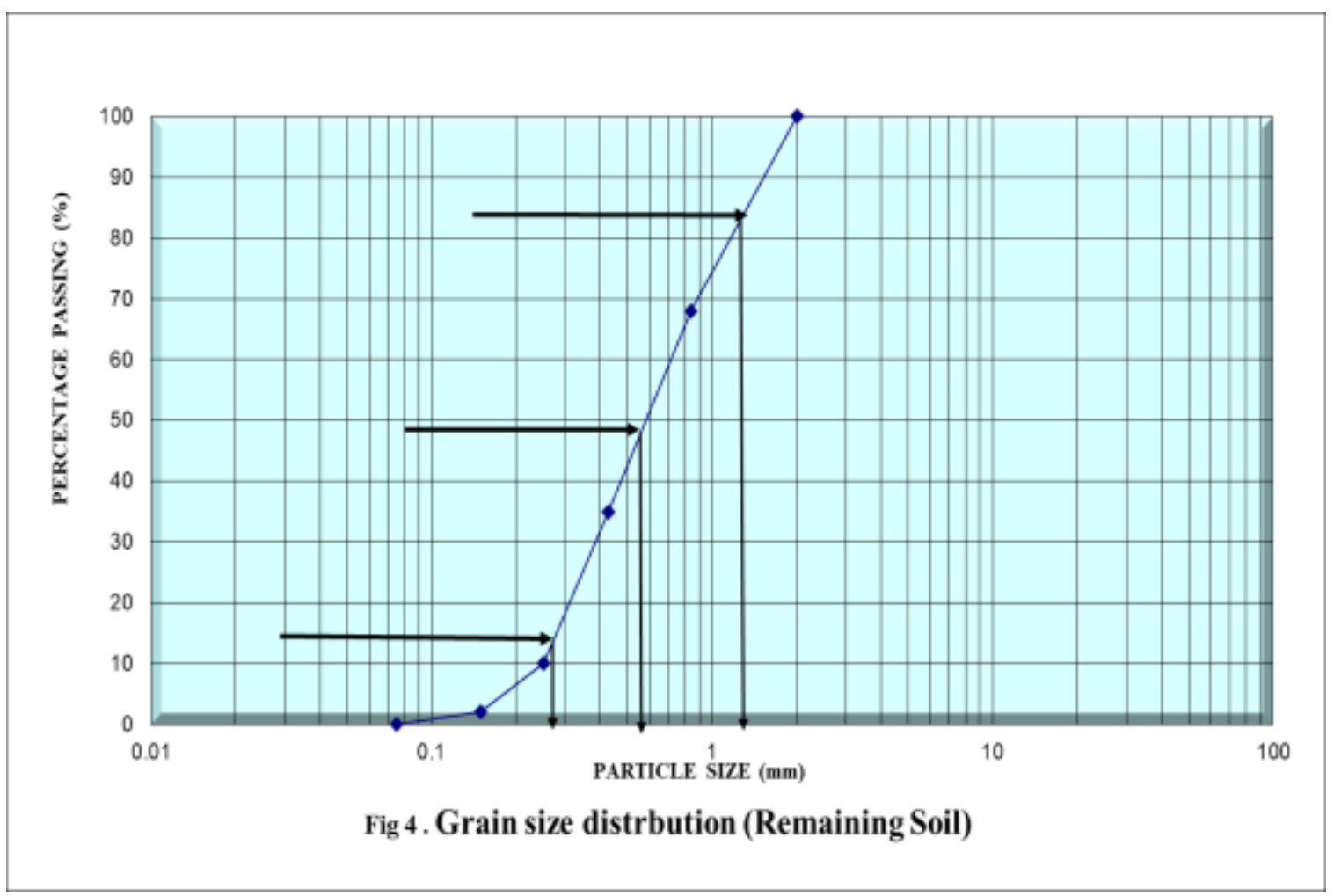

\section{B- Results of scour depth and length}

The tested sill relation between $\mathrm{L}_{\mathrm{sw}} / \mathrm{d}_{\mathrm{s}}$ and $\mathrm{F}_{\mathrm{r}}$ and $\mathrm{L}_{\mathrm{sw}} / \mathrm{d}_{\mathrm{s}}$ and $\mathrm{F}_{\mathrm{r}}$ were documented and plotted. Moreover, a regression analysis was carried out to correlate the two variables by means of polynomial equations to plot the suitable curve. In figures (5) and (6), the sill with angle 30 degree and $\mathrm{L}_{\mathrm{b}} / \mathrm{L}_{\mathrm{f}}=0.27$, attained a better ability in the reduction of the scour depth and length, where it was the best in energy dissipating.

\section{C-Comparative Study}

In figures (7) to (10) showed the best results in the reduction of scour depth and length in comparing the case of the original soil that was used and with the remaining soil with the same specifications as the remaining soil. The condition in which the sill with rotation angle 30 , position $\mathrm{L}_{\mathrm{b}} / \mathrm{L}_{\mathrm{f}}=0.27$ and using soil diameter $\mathrm{D}_{50} / \mathrm{B}$ range from $0.28 \mathrm{~m}$ to $1.5 \mathrm{~mm}$ led to the best scour depth reduction with a percentage of $10 \%$ to $15 \%$, and reduction scour length with a percentage of $18 \%$ to $20 \%$. 


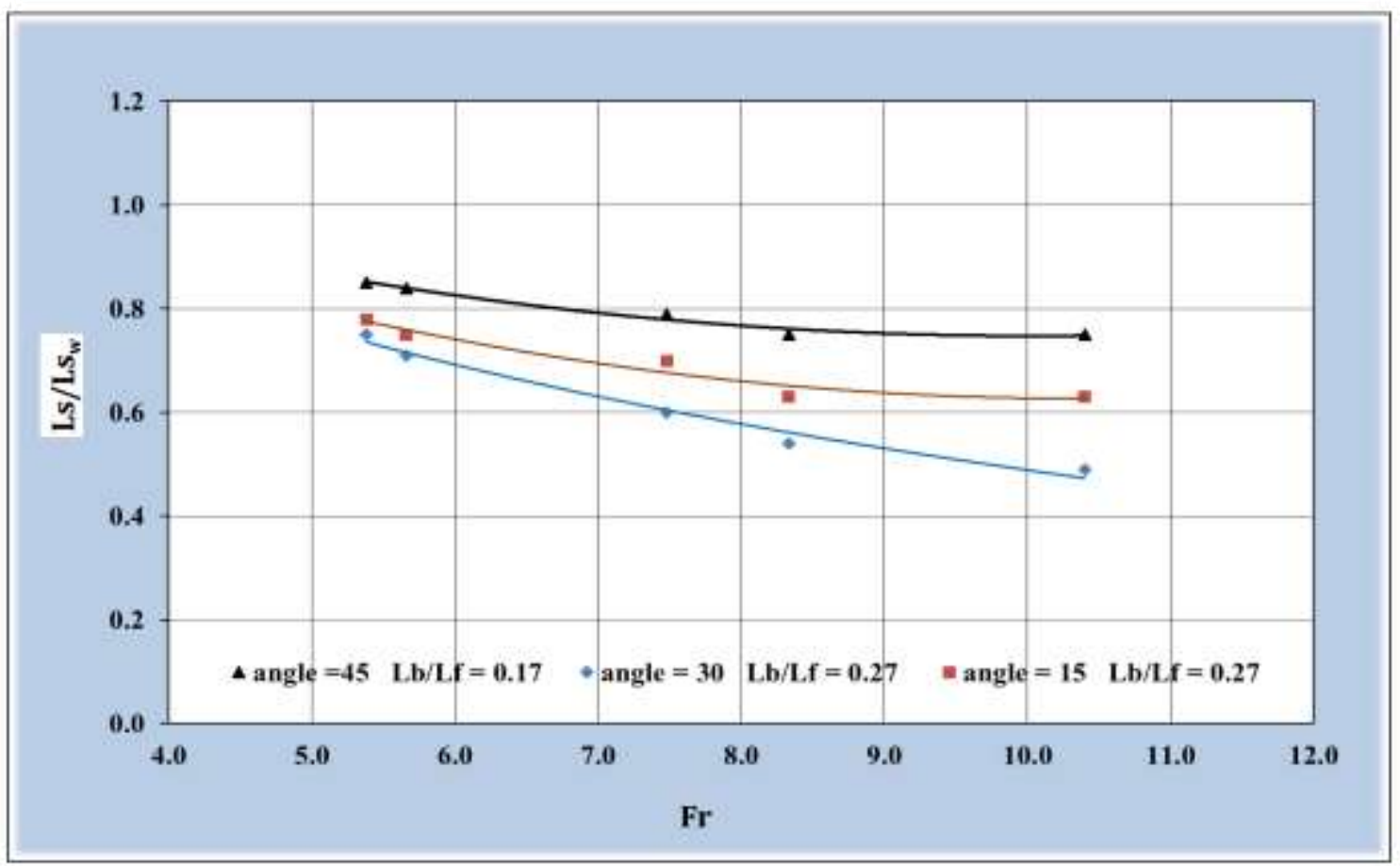

Fig 5: Relation between $\left(\mathrm{L}_{\mathrm{s}} / \mathrm{L}_{\mathrm{sw}}\right)$ and $\left(\mathrm{F}_{\mathrm{r}}\right)$

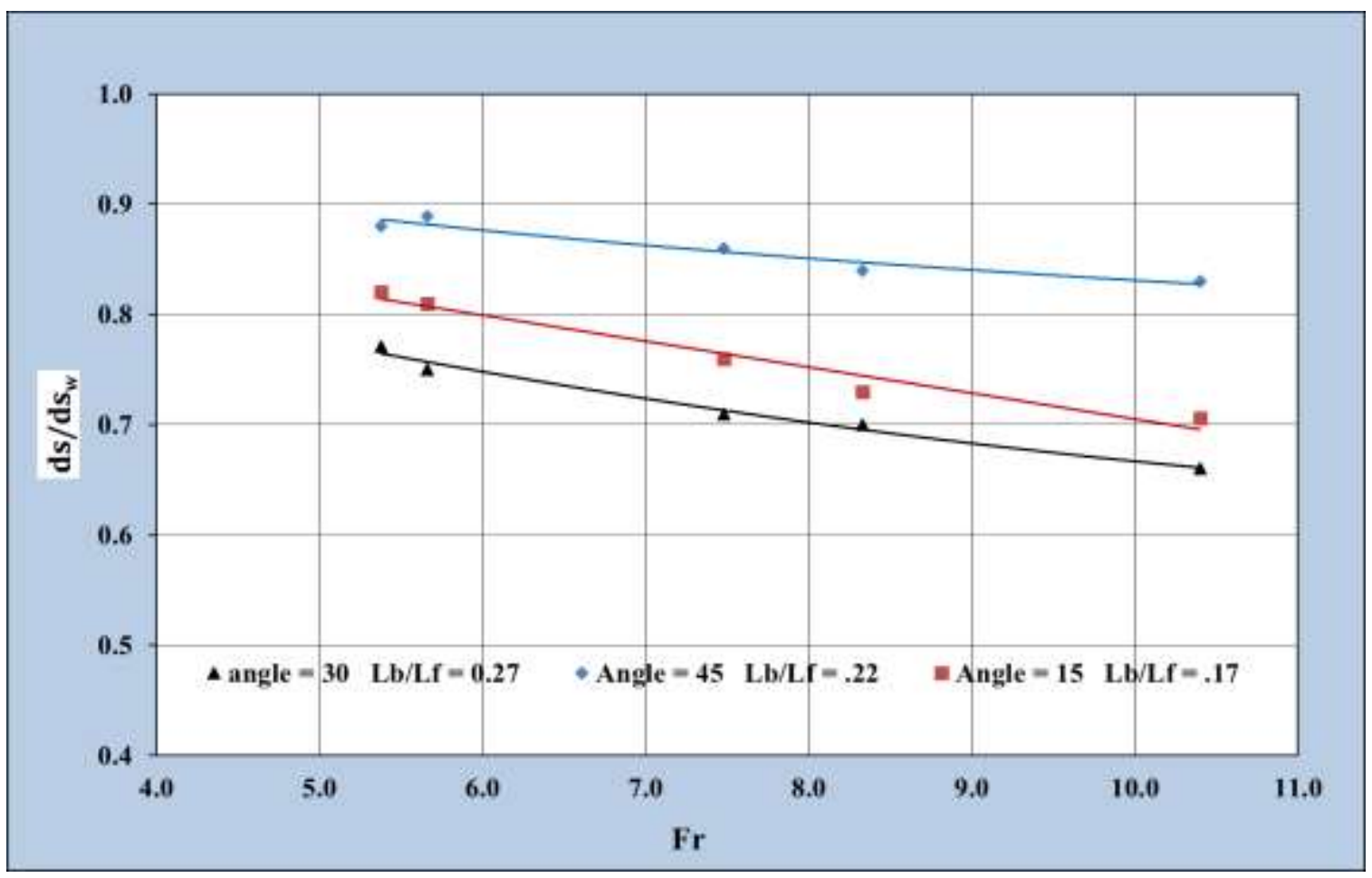

Fig 6: Relation between $\left(\mathrm{ds} / \mathrm{d}_{\mathrm{sw}}\right)$ and $\left(\mathrm{F}_{\mathrm{r}}\right)$ 


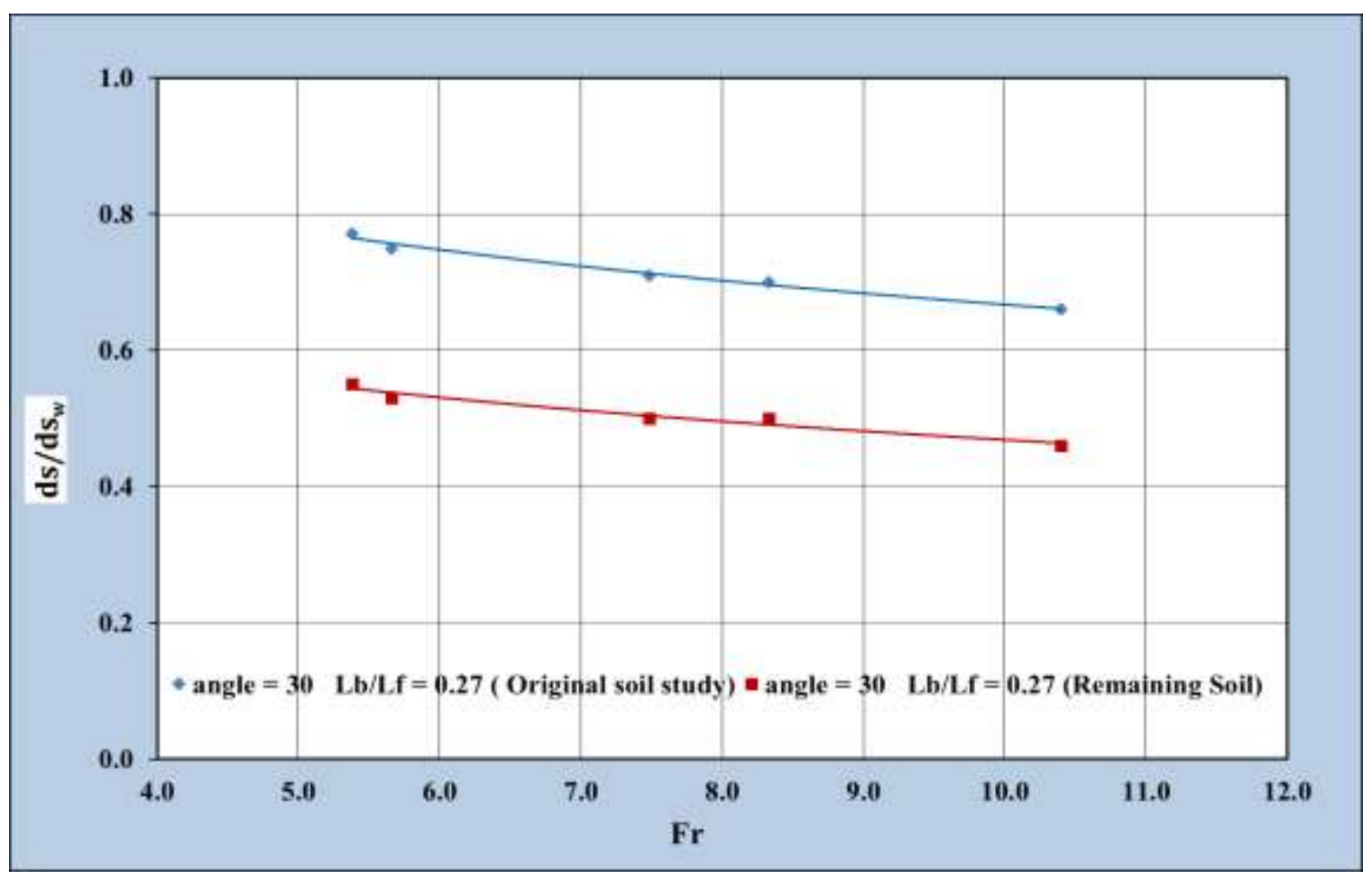

Fig 7: Relation between $\left(\mathrm{d}_{\mathrm{s}} / \mathrm{d}_{\mathrm{sw}}\right)$ and $\left(\mathrm{F}_{\mathrm{r}}\right)$

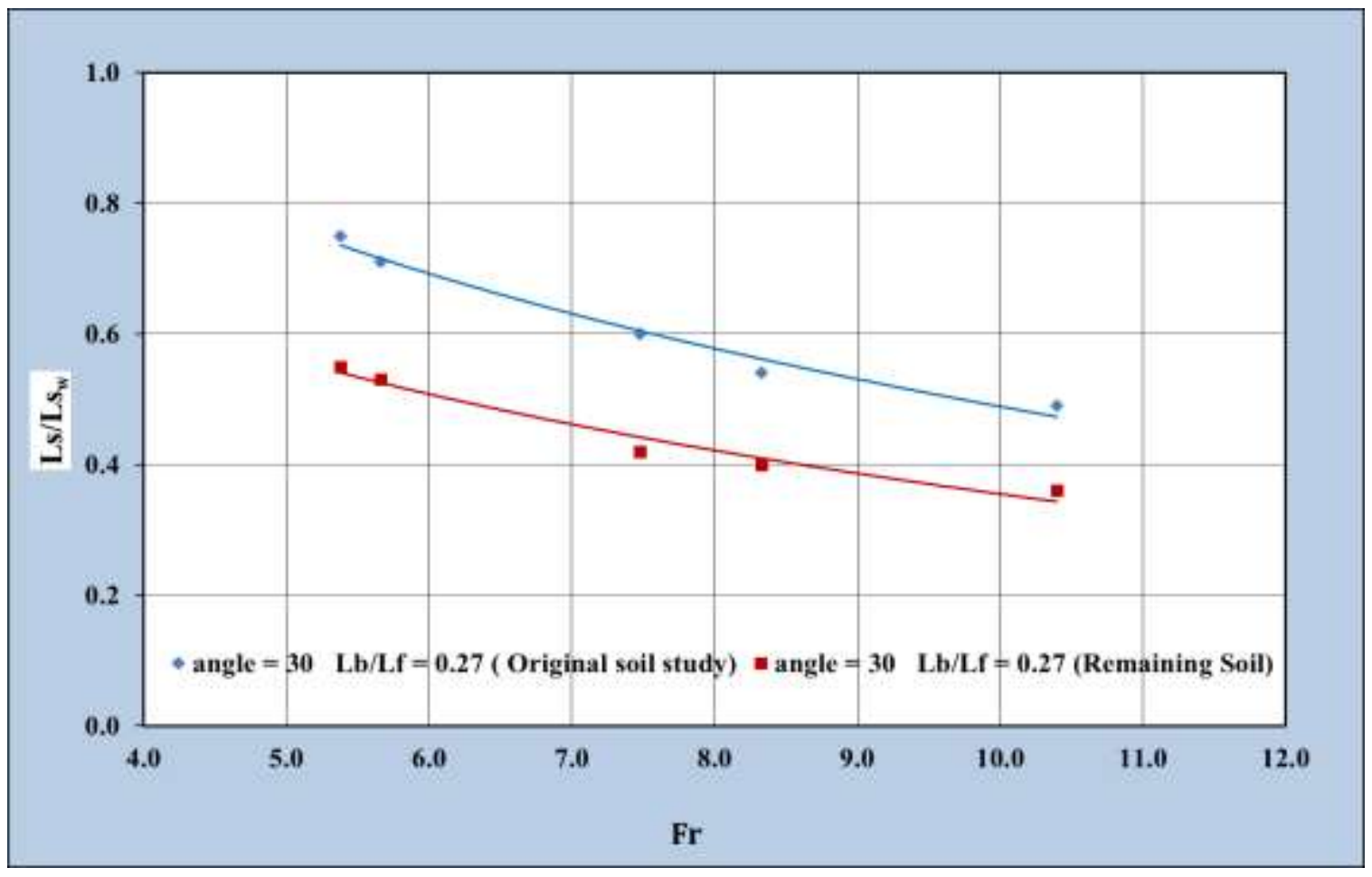

Fig 8: Relation between $\left(\mathrm{L}_{\mathrm{s}} / \mathrm{L}_{\mathrm{sw}}\right)$ and $\left(\mathrm{F}_{\mathrm{r}}\right)$ 


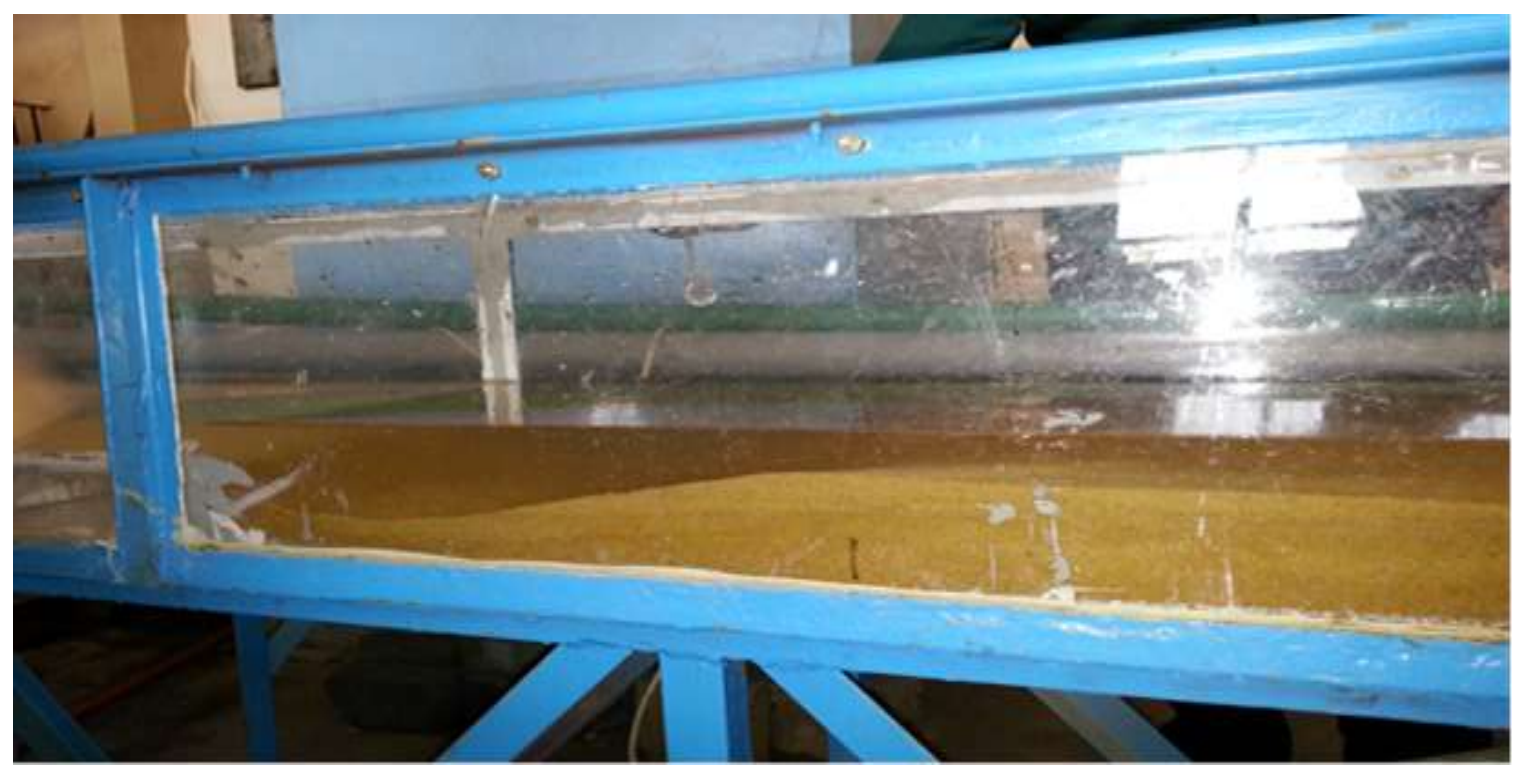

Fig 9: Local scour (original soil)

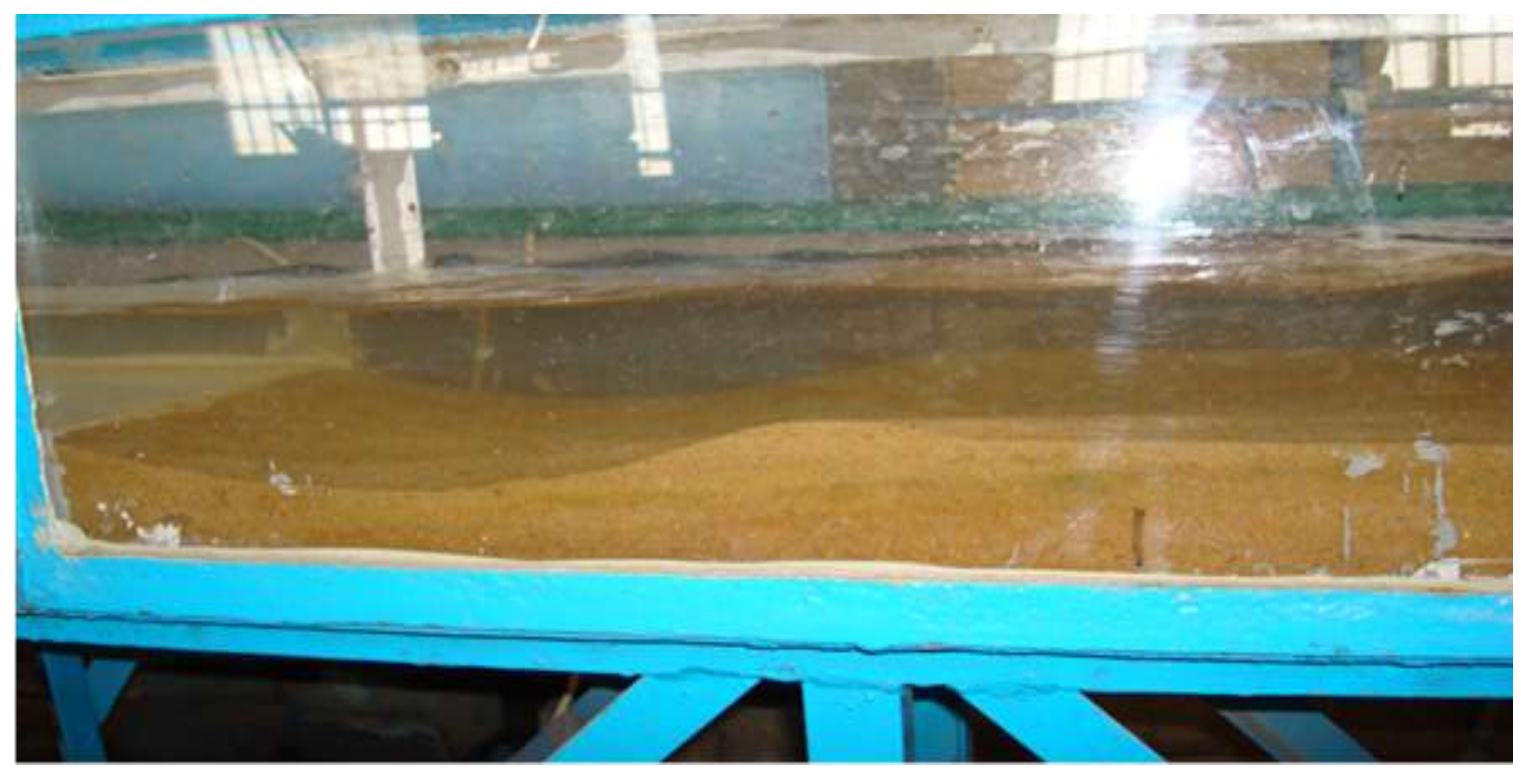

Fig 10: Local scour (Remaining soil) 


\section{6- Conclusion}

size of soil particles behind hydraulic structures has been studied experimentally for different conditions. From the current study, the following conclusions can be drawn:

1- The unconventional sill with angle of 30 with $\mathrm{L}_{b} / \mathrm{L}_{\mathrm{f}}=0.27$, had the ability to reduce scour length by $22 \%$ to $50 \%$

2- The unconventional sill with angle of 30 with $\mathrm{L}_{\mathrm{b}} / \mathrm{L}_{\mathrm{f}}=0.27$, had the ability to reduce scour depth by $22 \%$ to $33 \%$

3- The sill with angle of $30, \mathrm{~L}_{\mathrm{b}} / \mathrm{L}_{\mathrm{f}}=0.27$ showed the lowest scour depth using soil particles diameter $\mathrm{D}_{50} / \mathrm{B}$ range from $2.8 \times 10^{-4}$ to $1.5 \times 10^{-3}$ had the ability to reduce scour depth by $40 \%$ to $52 \%$. While he was able to reduce the scour length from $43 \%$ to $63 \%$

4- The reduction of scour depth and length for sill angle of $30^{\circ}, \mathrm{L}_{\mathrm{b}} / \mathrm{L}_{\mathrm{f}}=0.27$ is $10 \%$ to $15 \%$ lower than the maximum scour depth for the reference study. While he was able to reduce the scour length from $5.8 \times 10^{-4}$ to $2.2 \times 10^{-3}$ lower than the maximum scour length for the reference study.

5- Under the current study conditions, it is recommended to use soil particles of diameters range from $0.28 \mathrm{~m}$ to $1.5 \mathrm{~mm}$ for backfilling behind hydraulic structures.

\section{Notations:}

$\mathrm{B}=$ Width of channel (L).

$\mathrm{b}=$ Distance from pier to the side $(\mathrm{L})$.

$\mathrm{Q}=$ Flow rate $\left(\mathrm{L}^{3} \mathrm{~T}^{-1}\right)$.

$\mathrm{Y}=$ Normal water depth (L).

$\rho=$ Mass density of fluid $\left(\mathrm{ML}^{-3}\right)$.

$\mathrm{g}=$ Gravitational acceleration $\left(\mathrm{LT}^{-2}\right)$.

$\mathrm{d}_{\mathrm{s}}=$ Scour depth $(\mathrm{L})$.

$\mathrm{L}_{\mathrm{S}}=$ scour length (L).

$\mathrm{S} . \mathrm{G}=$ Soil Specific gravity (dimensionless).

$\mathrm{D}_{50}=$ Mean diameter of sediments (L).

$\mu=$ Dynamic viscosity $\left(\mathrm{ML}^{-1} \mathrm{~T}^{-1}\right)$.

$\mathrm{d}_{\mathrm{s}} / \mathrm{d}_{\mathrm{sw}}=$ depth scour ratio (dimensionless).

$\mathrm{L}_{\mathrm{s}} / \mathrm{y}=$ Relative scour length (dimensionless).

$\mathrm{Ls} / \mathrm{L}_{\mathrm{sw}}=$ Length scour ratio (dimensionless).

$\mathrm{D}_{50} / \mathrm{B}=$ Relative soil diameter (dimensionless).

$\mathrm{F}_{\mathrm{r}}=$ Froude's number (dimensionless). 


\section{Reference}

1. Shri Ram Chaurasia,2003: "Direct Equations for Hydraulic Jump Elements in Rectangular Horizontal Channel". Journal of Irrigation and Drainage Engineering, Vol. 129, No. 4, July/August, pp. 291-94.

2. El-Masry, A.A, 2001. "Influence of A Fully Angle Baffled Floor On Scour Behind A Hydraulic Structure" Mansoura Engeineering Journal Vol. 26, No. 4 Mansoura, Egypt 2001.

3. Abouel Atta, N. 1986,: "Study of the Effect of Location and Length of Roughened Beds on Flow Characteristics in Stilling Basins", Unpublished M.Sc. Thesis, Ain Shams University, Cairo, Egypt.

4. Ali, Mostafa, 2004: "The Efficiency Of Using Parabolic Sill As An Energy Dissipation Tool Downstream Hydraulic Structures". M.Sc.Thesis. Al-Azhar University, Faculty Of Engineering, Cairo, Egypt.

5. Walid M. Abd Elgalil, 2006.: "Effect of Side Flow on The Energy Down Stream Sluice Gate". Unpublished Ph.D Thesis, Al-Azhar University, Cairo, Egypt,

6. Ali ,Mostafa 2008 : "The Using Aprons Of Formed Surfaces As Energy Dissipaters Down Stream Hydraulic Structures". Ph.D. Thesis. Al-Azhar University, Faculty Of Engineering, Cairo, Egypt..

7. Ashour, Osama, 2008: "control og hydraulic jump by curved sill" M.Sc. Thesis. AlAzhar University, Faculty Of Engineering, Cairo, Egypt.

8. A Elmasry ,M.A.El-Enany, A.A Elmasry, 2003.M.F. Sobeih and E. Ussry "minimizing scour downstream control structures using semi-circular baffle blocks"Civil Engineering Research Magazine Vol (25) No (3) 2003 Page. 1437-1454.

9. Edward, Ching-Ruey LUO,2013. "Analysis and Application of Hydraulic Jump" International Journal of Engineering and Innovative Technology (IJEIT), Volume 3, Issue 2.

10. Ali, A. M., El Gamal, 2008. M. H., Negm, A. M., Helwa, M. F. and Saad, M. B. 'Investigation of flow characteristics downstream radial gates of hammadi barrages physical model' Twelfth International Water Technology Conference, IWTC12 2008, Alexandria, Egypt

11. Rajaratnam, N., 1965“Submerged Hydraulic Jump” J. of Hydraulic Engineering ASCE, Vol. 104, Hy.3.

12. Rajaratnam, N., 1976. Turbulent Jets Amsterdam-Oxford, New York USA, Elsevier Scientific Publishing Company.

13. Rodi, W., 1980“Turbulence Models and Their Application. 
14. Luo, C. R. , 1993 "Hydrodynamic Characteristics in Non-uniform Channels "Asian Institute of Technology, Thailand, Dissertation of Doctor of Engineering, WA93-1.

15. Federico, I., Marrone, S., Colagrossi, A., Aristodemo, F., \& Veltri, P. (2010). "Simulation of hydraulic jump through sph model". IDRA XXXII Italian Conference of Hydraulics and Hydraulic Construction.Palermo, Italy.

16. Chanson, H., and Brattberg, T.,2000. "Experimental study of the air-water shear flow in a hydraulic jump.'Int. J. Multiphase Flow, 26, pp. 583-607.

17. Lennon, J. M and Hill, D. F. "Particle Image Velocity Measurements of Undular and Hydraulic Jumps" Journal of Hydraulic Engineering (ASCE), 2006, pp. 1283-1294.

18. Chanson, H. (2004). The Hydraulics of Open Channel Flow: An Introduction. Oxford Elsevier Ltd.

19. : Mostafa Ali. Abdelaal “ Optimum Size of the soil Particles around Bridge Piers in the Curved Channels. Australian Journal of Basic and Applied Sciences, 13(7): 78-84. DOI: 10.22587/ajbas.2019.13.7.12

20. Ahmed Helmy.(2020). "Effect of soil particle size in reducing the Scour around bridge Piers at the Curved Channels". Life Sci J 2020;17(4):43-49]. ISSN: 1097-8135 (Print) / ISSN: 2372-613X (Online). 